\title{
RARE OCCUPATIONAL CAUSE OF NASAL SEPTUM PERFORATION: NICKEL EXPOSURE
}

\section{ERTUGRUL CAGRI BOLEK ${ }^{1}$, ABDULSAMET ERDEN², CAGRI KULEKCI ${ }^{3}$, UMUT KALYONCU $^{2}$, and OMER KARADAG ${ }^{2}$}

Hacettepe University, Ankara, Turkey

Faculty of Medicine

${ }^{1}$ Department of Internal Medicine

${ }^{2}$ Department of Internal Medicine, Division of Rheumatology

${ }^{3}$ Department of Otorhinolaryngology

\begin{abstract}
Many etiologies are held accountable for nasal septum perforations. Topical nasal drug usage, previous surgeries, trauma, nose picking, squamous cell carcinoma, some rheumatological disorders such as granulomatosis with polyangiitis (Wegener granulomatosis), some infectious diseases such as syphilis and leprosy are among the causes of the perforations. Occupational heavy metal exposures by inhalation rarely may also cause nasal septum perforation. Here, we present a 29-year-old patient without any known diseases, who is a worker at a metallic coating and nickel-plating factory, referred for investigation of his nasal cartilage septum perforation from an otorhinolaryngology clinic. The patient questioning, physical examination and laboratory assessment about rheumatic and infectious diseases were negative. There was a metallic smell in the breath during the physical examination. The analysis showed serum nickel level at $31 \mu \mathrm{g} / \mathrm{l}$ and urine nickel at $18 \mu \mathrm{g} / \mathrm{l}(84.11 \mu \mathrm{g} / \mathrm{g}$ creatinine). Other possible serum and urine heavy metal levels were within normal ranges. Nickel exposure is usually together with other heavy metals (chromium or cadmium), it is rarely alone. Nickel ingested by inhalation usually leads to respiratory problems such as reduced olfactory acuity, ulcers, septum perforation or tumors of the nasal sinuses. This case demonstrates the importance of occupational anamnesis and awareness of diagnosis. Int J Occup Med Environ Health 2017;30(6):963-967
\end{abstract}

Key words:

Occupational medicine, Nickel, Nickel exposure, Nasal septum perforation, Occupational toxic heavy metal exposure, Inhalation toxicity

\section{INTRODUCTION}

Perforations of the nasal septum may arise from various causes, but in most cases, they are results of topical nasal drug use, nose picking, past surgery and trauma. Septal perforation may be a sign of a systemic rheumatological disease such as vasculitis (i.e., granulomatosis with polyangiitis), infectious diseases (e.g., syphilis), neoplastic disorders and exposure to certain toxic substances. In this case study, we highlight the overlooked rare cause of septal perforation: occupational exposure to heavy metals exemplified by nickel exposure.

\section{CASE REPORT}

Here we present the case of a 29-year-old male patient without any prior diagnosis, referred for investigation at the otorhinolaryngology clinic for suspected nasal septal perforation.

Received: May 21, 2016. Accepted: September 22, 2016.

Corresponding author: E.C. Bolek, Hacettepe University, Faculty of Medicine, Department of Internal Medicine, Gevher Nesibe Street, 06100 Sihhiye/Ankara, Turkey (e-mail: ertugrulcagri@hotmail.com). 


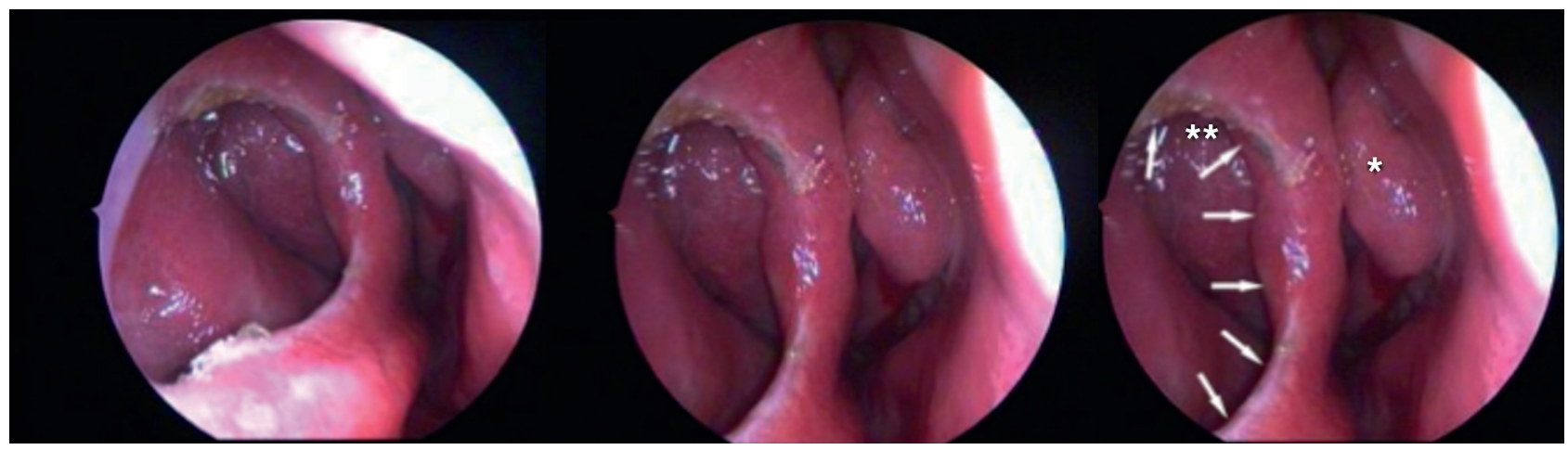

$\rightarrow$ perforation lines

* Left nasal cavity and middle turbinate

** Right nasal cavity and middle turbinate

Photo 1. Nasal cartilage septum perforation of a 29-year-old worker at a metallic coating and nickel-plating factory

Rhinoscopy examination revealed a 2-cm lesion in the septal side of the nasal cavity (Photo 1). The patient works in a metallic coating and nickel-plating factory with no history of use of nasal sprays, inhalers or illicit drugs like cocaine. He had not reported any medical history of trauma, surgery nor had he frequently picked his nose. During physical examination, no bloody nasal discharge was observed or no findings suggested neuropathy. Medical history, physical examination and laboratory assessment were all inconclusive for diagnosis of rheumatic and infectious diseases. Metallic smell in breath was noted during the physical examination.

Complete blood count (CBC), urine examination and biochemical parameters were normal. Erythrocyte sedimentation rate (ESR), C-reactive protein (CRP), antinuclear antibody (ANA), antineutrophil cytoplasmic antibody (ANCA), C3, C4, venereal disease research laboratory - rapid plasma reagin (VDRL-RPR) tests were all within normal range. Serum samples were sent to the Turkish Public Health Foundation Laboratory for assessment of exposure to heavy metals. The analysis showed elevated nickel (Ni) of $31 \mu \mathrm{g} / \mathrm{l}$ for blood serum sample (standard limits for this laboratory: 1-28 $\mu \mathrm{g} / \mathrm{l}$ ) and $18 \mu \mathrm{g} / \mathrm{l}=84.11 \mu \mathrm{g} / \mathrm{g}$ creatinine for urine sample (normal limits for this laboratory: $0.5-6.5 \mu \mathrm{g} / \mathrm{l})$. Other possible heavy metal levels (zinc, chromium, cadmium, lead) in blood serum and urine were normal.

The amount of Ni concentration in the working environment could not be quantified. The patient was also diagnosed with nasal septal perforation as a secondary to occupational nickel exposure. He had been working in this workplace for over 5 years. However, the patient had never sought medical attention for these complaints. For that reason, we did not know the exact time of the occurrence of the nasal perforation nor did we have any knowledge about prior evaluation of workplace risks for nickel exposure. We contacted the Occupational Diseases Unit about the case and we recommended a mandatory risk assessment for such workplaces in the future. Other employees at this workplace were also referred to the unit for assessment of possible exposures to $\mathrm{Ni}$.

\section{DISCUSSION}

Metal industries are very important for countries' economies. This is not only because they are a sine qua non for infrastructural development but also because they represent an important source of income for many people. Like in many business sectors and work division, occupational health is critical in this area too, especially for workers of 
such factories as metal refineries, mines and metal plating factories. In such places, there is significant level of exposure to occupational toxic heavy metals. Exposure to nickel, cadmium, chromium and lead has been reported in this setting. Specifically, nickel exposure alone is relatively rare and generally occurs in combination with chromium or cadmium.

Predominant exposure routes for nickel workers are inhalation of dusts, aerosols, nanoparticles, fumes [1]. Exposure by inhalation is generally negligible for other people except for tobacco smokers [1]. Individuals who smoke 40 cigarettes per day may be exposed to 2-23 $\mu \mathrm{g}$ of Ni via inhalation [2]. The general population is exposed to nickel via food and water or through inhalation of contaminated air [1].

Although heavy metals such as Ni cause contact dermatitis, exposure through inhalation may lead to more serious health problems. The presence of nickel above the normal range in the hair, blood and urine samples is an indicator for significant exposure. High Ni levels in the hair, blood or urine may give an idea about exposure, but Ni levels do not correlate with clinical findings in poisoning situations, unlike lead and mercury levels, both of which correlate well with clinical severity.

Inductively coupled plasma mass spectrometry (ICP-MS) method is commonly used in the measurement of Ni levels. The ICP-MS, which is a high-tech assay, allows for the qualitative or quantitative analysis of numerous elements in solid and liquid samples rapidly, inexpensively, sensitively and accurately. The detectable range of the quantitative analysis for many elements is $\mathrm{ppb}(\mu \mathrm{g} / \mathrm{kg})$. Our reference laboratory uses ICP-MS technique and normal range of serum nickel is $1-28 \mu \mathrm{g} / \mathrm{l}$ and urine nickel is $0.5-6.5 \mu \mathrm{g} / \mathrm{l}$. In the literature, the normal range for blood or urine nickel is inconsistent. Standard reference values for nickel concentration in healthy adult set by the Agency for Toxic Substances and Disease Registry (ATSDR) are $0.2 \mu \mathrm{g} / \mathrm{l}$ in serum and $1-3 \mu \mathrm{g} / \mathrm{l}$ in urine [1].
Some diseases such as myocardial infarction, burns, cirrhosis, stroke may alter the $\mathrm{Ni}$ concentration of certain samples [2]. Nickel concentration in biological samples were correlated to duration of exposure and levels decrease slowly after cessation of nickel exposure [3,4]. Occupational atmospheric monitoring is recommended for biological monitoring of workers exposed via inhalation [5].

The nasal septum perforation is in the list of conditions caused by Ni and its compounds is determined by the Ministry of Labour and Social Security of the Republic of Turkey. Assessment of occupational Ni exposure is determined by certain standards in accordance with regulations. Otolaryngologic, pulmonary, neurological and dermatological examinations must be done carefully. Limits considered by Turkey for exposure to Ni compounds account for $10 \mu \mathrm{g} / \mathrm{l}$ of plasma Ni levels, and for the nickel carbonyl gas - $10 \mu \mathrm{g} / 1$ of urine nickel levels. Periodic inspections start as work entrance examinations. Physicians should be careful about individuals who have symptoms or demonstrate signs for skin and respiratory tract. Skin and respiratory protection should be provided in addition to general engineering measures. Skin lesions should be examined. A special attention should be paid to assessment of the workplace atmosphere for nickel carbonyl gas concentrations. Nickel levels in workplace ambient air levels should be monitored. In Turkey, the permissible limit for nickel carbonyl in the air is $0.007 \mathrm{mg} / \mathrm{m}^{3}$.

It has been shown that $\mathrm{Ni}$ exposure may lead to mucosal damage, inflammation and fibrosis and harmful effects on the development of organism is studied on animals [1]. The most common Ni exposure-related disease is contact dermatitis with Ni plated jewelry and other objects of same nature [1]. Due to the fact that soluble $\mathrm{Ni}$ compounds are more toxic than others, Ni related to toxicities commonly occurs in the respiratory system [1]. Nickel plating and refinery workers may be at risk for rhinitis, sinusitis, nasal septal perforations, emphysema, 
fibrosis (pneumoconiosis) and asthma due to long-term exposure by inhalation $[1,2,6,7]$.

Nasal epithelial atrophy may occur in the case of individuals exposed to soluble nickel compounds [1]. Anosmia and hyposmia have been reported for workers exposed to heavy metals in Ni and cadmium industries due to possible atrophy of the olfactory epithelium [8]. In a case report in 2014, it is observed that a 26-years-old chemist working with Ni nanoparticles has facial flushing and upper airway symptoms such as nasal congestion, throat irritation and post nasal drip [9]. A study which is performed by Khlifi et al. suggests that toxic heavy metals such as cadmium and Ni have possible effects on development of nasosinusal polyposis disease [10]. Various long term studies have provided different results about the relationship between Ni exposure with lung and nasal cancers [11-15]. However, Ni compounds are known to be carcinogenic to humans and metallic $\mathrm{Ni}$ is considered as a possible carcinogen material [1].

Nickel (II) compounds have been shown to cause mitochondrial stress associated oxidative stress leading to cell injury of nasal epithelial cells in an in vitro study $[16,17]$. Nickel ions may be connected to DNA-histone complexes and are thought to be the cause of carcinogenesis through epigenetic effects on chromatin condensation [18,19]. However, toxic effects and carcinogenic mechanisms of Ni have not been fully understood yet.

The diagnosis of occupational Ni exposure-related nasal septum perforation of this case is only verified medically. After the case had been referred to occupational medicine, this unit planned an assessment of all other employees in the same factory for exposure risk and occupational diseases in the workplace. The unit also planned to inspect the workplace itself. The process is still on-going. We cannot actively pursue the next stage in the process because authors of this case report have different medical specialties each. The legal process will be initiated after the evaluation of the case is com- pleted by the occupational diseases unit. The workplace administration will be legally prosecuted, the provision of compensation for workers, necessary work-field changes for the patient will be provided according to the legislation.

\section{CONCLUSIONS}

The most important thing is sufficient awareness of the diagnosis of diseases associated with occupational exposure to toxic heavy metals. Detailed occupational history helps to diagnose. Prevention and reduction of time of exposure is crucial because some diseases are irreversible. Therefore, using the appropriate mask and construction of ventilation systems are highly recommended. In the case of any doubt, scanning the presence of toxic heavy metals in biological samples may give an idea for exposure, especially in individuals that are under risk. A specific chelator for Ni that may be used in therapy, such as in-lead exposure, is still yet-to-be-found. Patients should be referred to physicians at occupational health and safety centers for prevention and treatment of these conditions.

\section{REFERENCES}

1. Agency for Toxic Substances and Disease Registry. Toxicological profile for nickel. Atlanta: The Agency; 2005.

2. World Health Organization. Air quality guidelines for Europe. 2nd ed. Copenhagen: The Organization; 2000. p. 162-6.

3. Torjussen W, Andersen I. Nickel concentrations in nasal mucosa, plasma and urine in active and retired nickel workers. Ann Clin Lab Sci. 1979 Jul-Aug;9(4):289-98.

4. El-Shafei HM. Assessment of liver function among nickelplating workers in Egypt. East Mediterr Health J. 2011 Jun;17(6):490-4.

5. Morgan LG, Rouge PJ. Biological monitoring in nickel refinery workers. IARC Sci Publ. 1984;53:507-20.

6. Kowalska S, Sulkowski W. Perforation of the nasal septum of occupational origin. Med Pr. 1983;34(2):171-5. 
7. International Agency for Research on Cancer. Nickel and nickel compounds. In: Chromium, nickel and welding. IARC Monographs on the Evaluation of Carcinogenic Risks to Humans, No. 49. Lyon: The Agency; 1990. p. 257-445.

8. Sunderman FW Jr. Nasal toxicity, carcinogenicity, and olfactory uptake of metals. Ann Clin Lab Sci. 2001 Jan;31 (1):3-24.

9. Journey WS, Goldman RH. Occupational handling of nickel nanoparticles: A case report. Am J Ind Med. 2014 Sep;57(9):1073-6, https://doi.org/10.1002/ajim.22344.

10. Khlifi R, Olmedo P, Gil F, Hammami B, Hamza-Chaffai A. Cadmium and nickel in blood of Tunisian population and risk of nasosinusal polyposis disease. Environ Sci Pollut Res Int. 2015 Mar;22(5):3586-93, https://doi.org/10.1007/s11356014-3619-8.

11. Horiguchi S, Morinaga K, Endo G. Epidemiological study of mortality from cancer among chromium platers. Asia Pac J Public Health. 1990;4(2-3):169-74, https://doi.org/ $10.1177 / 101053959000400316$.

12. Sivulka DJ, Seilkop SK, Lascelles K, Conard BR, Jones SF, Collinson EC. Reconstruction of historical exposures at Welsh nickel refinery (1953-2000). Ann Occup Hyg. 2014 Jul;58(6):736-60, https://doi.org/10.1093/annhyg/meu022.

13. Grimsrud TK, Andersen A. Unrecognized risks of nickelrelated respirotary cancer among Canadian electrolysis workers. Scand J Work Environ Health. 2012 Nov;38(6): 503-15, https://doi.org/10.5271/sjweh.3274.

14. Lightfoot N, Berriault C, Semenciw R. Mortality and cancer incidence in a nickel cohort. Occup Med (Lond). 2010 May;60(3):211-8, https://doi.org/10.1093/occmed/kqp197.

15. Sorahan T, Williams SP. Mortality of workers at a nickel carbonyl refinery, 1958-2000. Occup Environ Med. 2005 Feb;62(2):80-5, https://doi.org/10.1136/oem.2004.014985.

16. Lee YJ, Lim SS, Baek BJ, An J-M, Nam H-S, Woo K-M, et al. Nickel(II)-induced nasal epithelial toxicity and oxidative mitochondrial damage. Environ Toxicol Pharmacol. 2016 Mar;42:76-84, https://doi.org/10.1016/j.etap.2016.01.005.

17. Freitas M, Barcellos-de-Souza P, Barja-Fidalgo C, Fernandes E. Nickel induces apoptosis in human neutrophils. Biometals. 2013 Feb;26(1):13-21, https://doi.org/10.1007/s1 0534-012-9590-2.

18. Sun H, Shamy M, Costa M. Nickel and epigenetic gene silencing. Genes (Basel). 2013 Oct 25;4(4):583-95, https://doi. org/10.3390/genes4040583.

19. Arita A, Munoz A, Chervona Y, Niu J, Qu Q, Zhao N, et al. Gene expression profiles in peripheral blood mononuclear cells of Chinese nickel refinery workers with high exposures to nickel and control subjects. Cancer Epidemiol Biomarkers Prev. 2013 Feb;22(2):261-9, https://doi.org/10.1158/10559965.epi-12-1011.

This work is available in Open Access model and licensed under a Creative Commons Attribution-NonCommercial 3.0 Poland License - http://creativecommons.org/ licenses/by-nc/3.0/pl/deed.en. 